\title{
Medical malpractice in spine surgery: a review
}

\author{
Zachary A. Medress, MD, Michael C. Jin, BS, Austin Feng, BA, Kunal Varshneya, BS, and \\ Anand Veeravagu, MD
}

\author{
Department of Neurosurgery, Stanford University, Stanford, Califiornia
}

\begin{abstract}
Medical malpractice is an important but often underappreciated topic within neurosurgery, particularly for surgeons in the early phases of practice. The practice of spinal neurosurgery involves substantial risk for litigation, as both the natural history of the conditions being treated and the operations being performed almost always carry the risk of permanent damage to the spinal cord or nerve roots, a cardiopulmonary event, death, or other dire outcomes. In this review, the authors discuss important topics related to medical malpractice in spine surgery, including tort reform, trends and frequency of litigation claims in spine surgery, wrong-level and wrong-site surgery, catastrophic outcomes including spinal cord injury and death, and ethical considerations.
\end{abstract}

https://thejns.org/doi/abs/10.3171/2020.8.FOCUS20602

KEYWORDS medical malpractice; spine surgery; medicolegal; tort reform; ethics

$\mathrm{T}$ HE practice of spinal neurosurgery involves a high inherent risk of litigation due to the nature of conditions being treated, the need for instrumentation often placed in close proximity to critical neurovascular structures, and the unforgiving nature of the spinal cord and nerve roots. There is evidence that neurosurgery, and spinal neurosurgery in particular, is among the highest-risk specialties with regard to risk of malpractice claims. In an analysis of 40,916 physicians from 1991 to $2005,7.4 \%$ of physicians received a malpractice claim. ${ }^{1}$ Of the 25 medical and surgical specialties listed, neurosurgeons had the highest percentage of practitioners receiving a claim each year at $19.1 \%$. In this review, we discuss major medicolegal topics relating to malpractice in spine surgery, including tort reform, trends of malpractice claims related to spine surgery in the US, medicolegal considerations after catastrophic outcomes including spinal cord injury and death, and ethical considerations related to the disclosure of errors in spine surgery.

\section{Tort Reform and Spine Surgery}

Of particular significance to surgeons practicing in subspecialties with high litigation risk, ${ }^{2}$ tort laws establish the guidelines for addressing malpractice concerns and lawsuits. The landscape of tort laws is geographically heterogeneous, as the framework for medical litigation is established individually by each state rather than the federal government. A major component of tort reform involves establishment of state-level malpractice damage capitation, and recent decades have seen a major evolution in regulations. In this section, we outline landmark legislation and its impact on medical lawsuit claims broadly across medical disciplines and specifically as it pertains to spine surgery.

In setting the stage for understanding the modern status quo of medical liability and lawsuit costs, surveying historical trends in claim volume is crucial. Prior estimates of malpractice claim volume suggest a 100-fold increase between 1930 and 1950, while the period between 1970 and 1975 saw a further doubling of annual lawsuit volume to approximately 20,000 claims. $^{3}$ In response to this protracted rise in medical litigation, malpractice insurance premiums similarly grew. Between 1960 and 1970, surgeon insurance premiums burgeoned by nearly $1000 \%, 4$ this increase was especially pronounced in the nation's most populous state (California) and city (New York City), which experienced annual cost increases $25 \%$ greater than the nation as a whole. ${ }^{4,5}$ One striking example of this is the increase in premiums required of New York neurosur- 

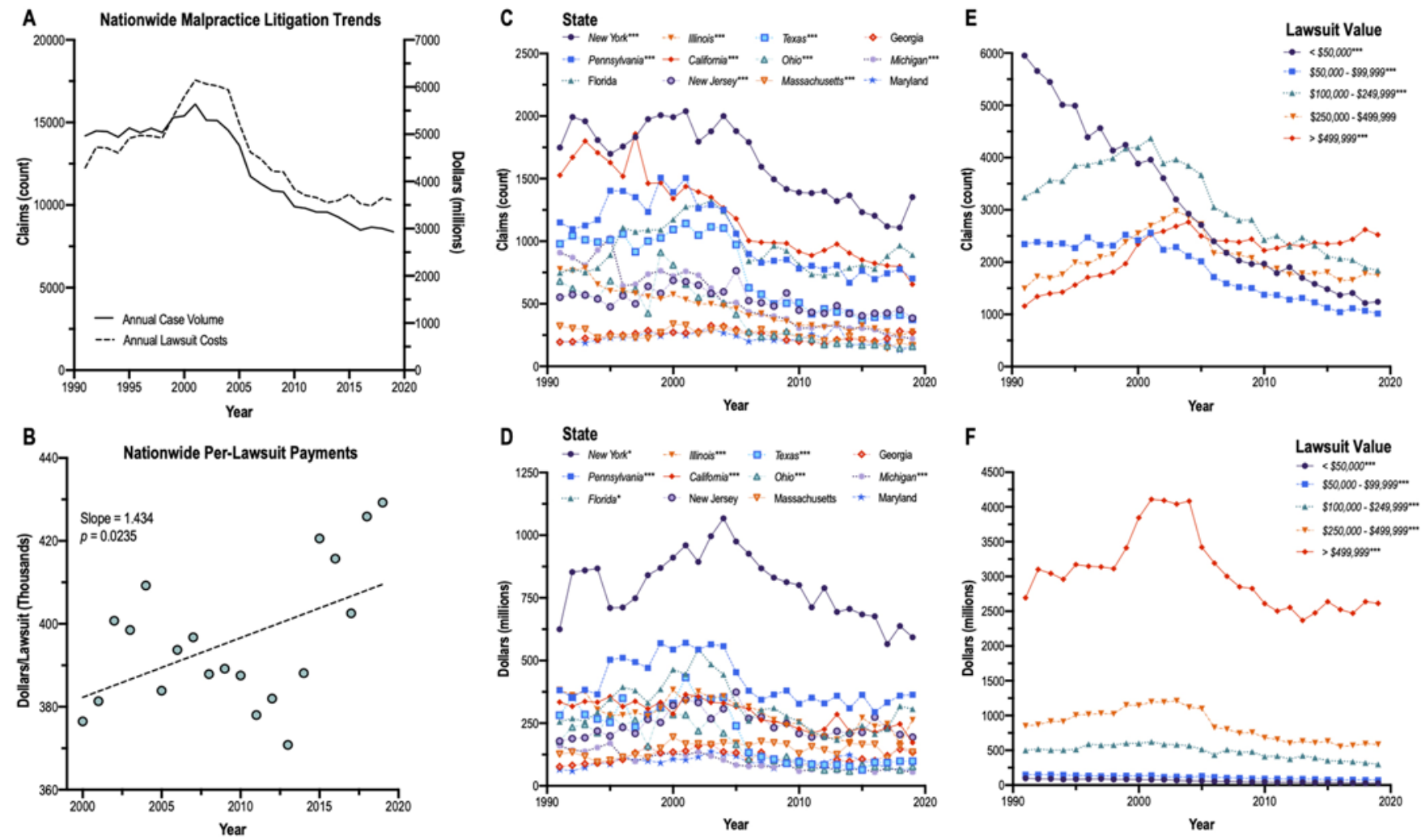

FIG. 1. National trends in malpractice litigation among physicians. Although overall litigation volume and total costs have decreased over the past 2 decades $(\mathbf{A})$, the per-lawsuit value of malpractice litigation has risen significantly over the past 20 years (B). Further breakdown of malpractice litigation trends in volume (C) and costs (D) by state is shown, depicting the top 12 states with the highest malpractice litigation costs over the past 3 decades. Additional breakdown is given by per-lawsuit cost (E and $F)$. All $p$ values reflect two-sided hypothesis testing for a nonzero trendline slope. ${ }^{*} p<0.05,{ }^{* *} p<0.01,{ }^{* * *} p<0.001$. All data were extracted from the National Practitioner Data Bank ${ }^{53}$ and reflect all MD and DO physicians.

geons and orthopedic surgeons from $\$ 819$ dollars in 1965 to $\$ 14,000$ in 1974 to a proposed $\$ 43,000$ in $1975 .^{3}$ The late 1970s, however, saw major shifts in the legal handling of malpractice cases, as tort reform efforts began to emerge in individual states. In one of the earliest and most aggressive state-led initiatives, California ratified the Medical Injury Compensation Reform Act in 1975, which enacted a maximum flat cap of $\$ 250,000$ on noneconomic damages while comprehensively reworking the longitudinal handling of malpractice cases. ${ }^{6}$ Shortly thereafter, 16 other states enacted malpractice litigation reforms, and by 1986 every state had ratified new legislation governing the handling of medical malpractice lawsuits. ${ }^{7}$ Reform extent ranged broadly but, generally, the most frequently addressed issues involved malpractice claim limits and payment scheduling, attorney fees, collateral source rules, and pretrial screening panels.

The marginal impact of this legislation on the handling of medical malpractice complaints is difficult to directly quantify, as the myriad factors contributing to trends in medicolegal claims span often-intangible aspects of medicine, law, and economics. However, continued efforts to improve and modernize tort laws pertaining to malpractice litigation have certainly contributed to the ever-dynamic landscape of malpractice lawsuits and their resolution.
As documented by the National Practitioner Data Bank, ${ }^{8}$ more than 350,000 lawsuits costing over $\$ 132$ billion (US, adjusted to 2019 dollar values) have been filed between the start of 1991 and the end of 2019. Since 2000, nationwide case volume and litigation reparation costs (inflationadjusted) have decreased significantly (Fig. 1A). The past 2 decades have seen annual physician malpractice case volume decrease by approximately 450 cases per year and annual malpractice costs decrease by approximately $\$ 150$ million per year. Despite this, it remains noteworthy that the average inflation-adjusted value per case has increased during this time period by approximately $\$ 1500$ per year, from approximately $\$ 376,000$ in 2000 to nearly $\$ 430,000$ in 2019 (Fig. 1B). Similar trends may be observed in the 12 states with the highest malpractice litigation cost totals since 1991, where the majority of states have experienced decreases in case volume (Fig. 1C) and total malpractice payment costs (Fig. 1D). However, reinforcing the assertion that per-lawsuit payments have increased, the number of cases in excess of $\$ 500,000$ has increased significantly between 1991 and 2019, while those less than \$250,000 have decreased during that period (Fig. 1E). These highvalue litigation cases constitute a significant portion of total malpractice payouts (Fig. 1F) and reiterate the importance of defensive medicine across physician specialties. 

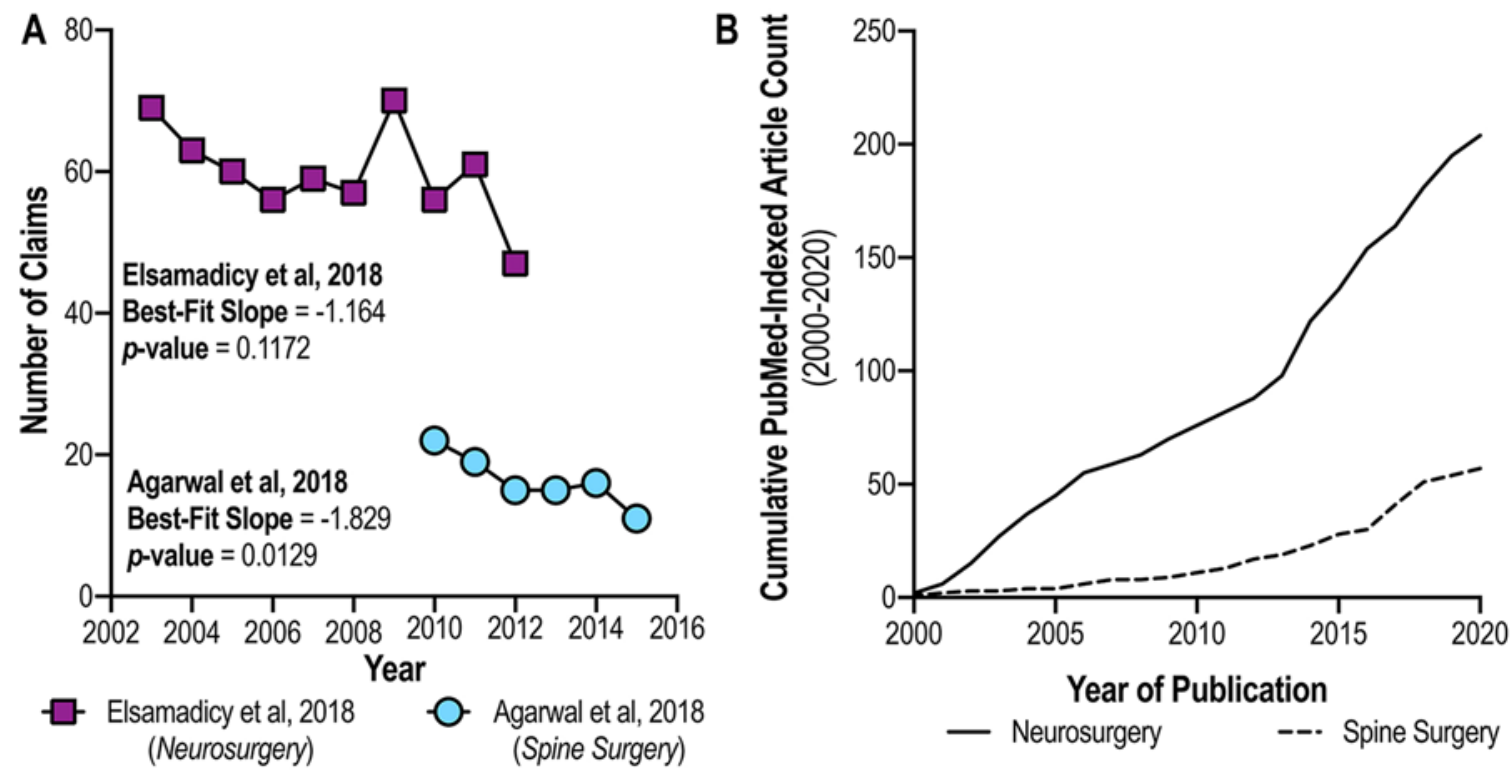

FIG. 2. Trends in malpractice litigation and literature in neurosurgery and spine surgery. A: Per-year malpractice litigation case volume in neurosurgery ${ }^{11}$ and spine surgery. ${ }^{12} \mathrm{~B}$ : Cumulative peer-reviewed literature volume over the past 20 years queried using the following search strategies: "neurosurgery AND malpractice" (neurosurgery); "spine AND surgery AND malpractice" (spine surgery).

\section{Trends and Frequency of Medicolegal Malpractice Claims in Spine Surgery}

Historically, neurosurgeons have faced high rates of malpractice lawsuits; Jena et al. noted that not only did nearly $20 \%$ of neurosurgeons face at least one malpractice claim annually between 1991 and 2005, but also median annual payments to plaintiffs were the highest in neurosurgery at more than $\$ 200,000$ per year. ${ }^{1}$ Malpractice claims were particularly common following spine surgery compared to other neurosurgical subspecialties, with estimates suggesting that nearly $60 \%$ of cases involve spine surgeons while the next most common subspecialty, general neurosurgery, only constituted $15 \%$ of cases. ${ }^{9,10}$ This skew is further exemplified by surveying the most frequent medical conditions among plaintiffs. Of the malpractice claims served to neurosurgeons between 2003 and 2012, the three most common conditions (intervertebral disc disease, back disorders/pain, and spinal stenosis) together comprised over $40 \%$ of all cases and payments totaled nearly $\$ 105$ million. ${ }^{11}$ In a query of the Thomson Reuters Westlaw online legal database, Agarwal et al. identified 98 malpractice cases filed between 2010 and 2015 involving spine operations. ${ }^{12}$ The vast majority $(79 \%)$ were elective procedures, in which the predominantly cited reasons included "lack of informed consent" (29.9\%), "failure to treat" (20.8\%), and "failure to diagnose" (19.5). Procedural error was more frequently cited as a reason for litigation of elective procedures $(71.4 \%)$ than for emergent procedures (14.3\%).

Elsamadicy et al. ${ }^{11}$ and Agarwal et al. ${ }^{12}$ offer two independent analyses of neurosurgery- and spine-specific malpractice, respectively, from two data sets: the Physician Insurers Association of America Data Sharing Project, and the Thomson Reuters Westlaw legal database. Although neither study represents a wholly comprehensive collection of malpractice litigation attributable to neurosurgeons or spine surgeons, internal comparisons of temporal case distribution may help identify recent trends in litigation volume. A nonsignificant downward-sloping trend was present in the neurosurgical data set; ${ }^{11}$ by comparison, spine-specific litigation case volume ${ }^{12}$ more closely mirrors the previously mentioned trends among all physician providers, suggesting a more consistent decrease in annual malpractice lawsuits after 2010 (Fig. 2A). Though systematic studies evaluating the robustness and etiology of these declines are warranted, it may be speculated that increasing education on malpractice litigation and expanded adoption of defensive medicine may have contributed to the observed trends. A keyword-based query of neurosurgery and spine surgery articles related to medical malpractice indexed on PubMed between the years 2000 and 2020 reveals that in that time span, 204 and 57 peerreviewed papers, respectively, were published (Fig. 2B). This ever-expanding wealth of knowledge and literature helps to cultivate an understanding of malpractice litigation, in turn enabling neurosurgeons to provide quality care in accordance with patient expectations.

\section{Spinal Cord Injury}

Nearly 5\% of spinal cord injuries result from medical or surgical procedures. ${ }^{13}$ In a systematic query of the VerdictSearch database by Daniels et al., spinal cord injury comprised 60 (25.6\%) of 234 qualifying malpractice litigation cases between 1988 and 2015. ${ }^{14}$ Catastrophic complications, including not only spinal cord injury but also brain injury and death, significantly increased the likelihood of a plaintiff-favoring verdict or settlement (66.7\%). A sepa- 
rate study using the VerdictSearch database assessed the etiologies of spinal cord injury in malpractice lawsuits and their association with litigation outcomes. ${ }^{15}$ Notably, compared to claims involving delayed or incorrect diagnoses, those linked to errors in therapy were significantly more likely to rule in favor of the defense $(56.0 \%$ vs $20.8 \%)$. Across all spinal cord injury cases, the monetary value of court decisions was similar regardless of anatomical location and ranged from a median of $\$ 750,000$ for lumbar injuries to $\$ 1.9$ million for thoracic injuries. High-value decisions were frequently seen linked to cervical and thoracic injuries, where the 75th percentiles of monetary reparation were $\$ 8.3$ and $\$ 3.95$ million, respectively, compared to less than $\$ 2$ million for lumbar injuries. More than $80 \%$ of lawsuits stemming from delayed injury diagnosis were initially caused by an initial lack of neuroimaging, reinforcing the importance of early imaging when spinal cord injury is suspected. Other studies have demonstrated similar findings: for example, an earlier study revealed that a minority ( 8 of $20,40 \%$ ) of lawsuits involving missed cervical spine injuries were ruled in favor of the defendant, and reparation awards, when adjusted to 2020 US dollars, averaged approximately $\$ 4.1$ million. ${ }^{16}$

It is well established that neurosurgery carries a high risk of malpractice litigation and mindfulness of defensive medicine remains important. As previously established, lawsuits resulting from errors or delays in diagnosis of spinal cord injury are particularly challenging; from these studies, a reasonable hypothesis can be drawn that early and frequent neuroimaging may obviate the possibility of future litigation. In a real-world study surveying over 824 physicians in high-risk specialties including neurosurgery, Studdert et al. identified a high rate of imaging use in "clinically unnecessary" situations and cites a tendency of providers to avoid cases perceived to carry elevated litigation risk. ${ }^{17}$ Specifically, among neurosurgeons surveyed, nearly $60 \%$ cited utilizing CT, MRI, and radiography as assurance practices, even when "clinically unnecessary." These practice patterns present an important dichotomy juxtaposing clinical guidelines and prior literature, which remains divided regarding the use of early advanced imaging in patients presenting with acute-onset back pain. ${ }^{18}$ Furthermore, plain-film radiographs may miss a subset of spinal cord injury cases with structural anomalies detectable only by MRI. ${ }^{19}$

\section{Wrong-Level Surgery}

Wrong-site surgeries are surgical procedures performed on the wrong patient or side. Designated as sentinel events by the Joint Commission on Accreditation of Healthcare Organizations (JC), they have been the second most commonly reported event from 1995 to 2005, involving 455 (12.8\%) of 3548 events. ${ }^{20}$ With regard to spine surgery, wrong-level surgery is a particular subcategory of wrong-site surgery, defined as the correct procedure and site but incorrect level or portion of the operative field. ${ }^{21}$ A query from the American Board or Orthopedic Surgery's database of spinal procedures between 1999 and 2010 calculated a rate of $0.041 \%$ for wrong-level surgery. This estimate falls into the range of wrong-level surgery rates, $0.09-4.5$ per 10,000 surgeries $(0.0009 \%-0.045 \%)$, determined by a systematic review. ${ }^{20}$ Additionally, most incorrect-level procedures are performed in the lumbar spine. ${ }^{22,23}$ While seemingly rare, the occurrence of wronglevel surgery in one's career cannot be underestimated. In a survey of AANS members, Mody et al. found that $50 \%$ of responders performed at least one wrong-level surgery. ${ }^{24}$ In the medicolegal context, wrong-level surgery frequently results in litigation, with prior indemnities as high as $\$ 1.5$ million. ${ }^{25}$

In 2004, the JC developed the Universal Protocol (UP) that highlighted preoperative verification, site marking, and surgical "time-out"; all accredited hospitals have since been required to implement the UP. ${ }^{24}$ For spine procedures, this includes stating and verifying the level, and side if applicable, intended to be operated upon. Vachhani and Klopfenstein found a statistically significant reduction of wrong-site surgery incidence after UP implementation; 93.3\% of wrong-site cases were wrong-level spine surgeries. ${ }^{26}$ However, further analysis by Algie et al. determined that annual incidence of wrong-site surgery was already trending downward prior to UP implementation. ${ }^{27}$ Given confounding factors such as increased adoption of intraoperative imaging, the impact of UP is unclear. ${ }^{28}$ In a survey of neurological surgeons, Groff et al. found that only $40 \%$ of respondents believed that the UP had reduced wrong-level errors..$^{29}$ Certain challenges of wronglevel surgeries cannot be overcome by the standardized, systems-based approach of the UP. Integration of both pre- and intraoperative imaging with the knowledge of the patient's pathology while navigating spinal anatomy is a complex task that can only be accomplished by the spine surgeon. Patient-level characteristics from congenital variants to deformities of anatomy need to be appreciated and integrated into a patient-specific intraoperative plan..$^{20,28} \mathrm{In}$ some cases, an operative level may be mislabeled in the preoperative radiological examination, an error that may be carried forward to the time of the operation.

Intraoperative imaging is a major key to determining the correct spinal level. ${ }^{20,25,30}$ Site marking alone has proven to be insufficient. Nassr et al. determined needle localization during anterior cervical surgery incorrectly marked the spinal level at a $17 \%$ rate. ${ }^{31}$ With newer techniques and technologies, various localization modalities have been developed that utilize fluoroscopy or plain radiography in conjunction with fiducial marking of an anatomical landmark. ${ }^{32-34}$ Still, the continued prevalence of wrong-level surgery underscores its limitations. While intraoperative imaging has mostly become common practice, its use is not universal among providers. ${ }^{24,29}$ Only $80 \%$ of respondents strictly follow guidelines for intraoperative radiography. ${ }^{29}$ Furthermore, intraoperative imaging is no panacea to wrong-level prevention. Miscounting or misinterpretation of spinal anatomy and patient obesity or operating room limitations leading to poor radiograph quality are all potential factors that negate the usefulness of imaging. ${ }^{25}$ In addition, there is also notable heterogeneity in the specific imaging methods and other preventative measures adopted. ${ }^{24,29}$ From the perspective of litigation, utilization of intraoperative imaging does not prevent liability. Fager reveals that in 16 malpractice cases of wrong- 
level surgery, all had intraoperative imaging performed. ${ }^{35}$ Goodkin and Laska demonstrate no obvious association between its use and the jury's verdict. ${ }^{25}$ Thus, as with any informed consent process, direct and clear communication with the patient about the potential risks of spine surgery remains crucial.

\section{Cauda Equina Syndrome}

Cauda equina syndrome (CES) is a neurosurgical emergency characterized by severe compression of the cauda equina nerve roots in the central canal by a herniated disc, tumor, hematoma, abscess, or fractured bone fragments leading to paraparesis, saddle anesthesia, and bowel and bladder incontinence. There is strong evidence supporting the need for prompt diagnosis and surgical intervention in cases of CES, with delayed treatment associated with permanent motor deficits and loss of bowel and bladder function. With failures to diagnose and treat among the most commonly cited reasons for malpractice cases, particularly in spine surgery, CES is an important condition to consider due to significant medicolegal consequences. ${ }^{9,11,12}$ CES is an absolute indication for surgical emergency of the lumbar spine given the potential for permanent neurological damage affecting normal bladder, bowel, and sexual function. ${ }^{36,37}$ Reflecting the serious impact on patient well-being and quality of life, malpractice for CES can be very costly. Studies from the United Kingdom (UK) report average payments of $£ 177,331-£ 336,000$ (\$292,596$\$ 554,400$ US) per case at 2003 prices. A review of CES cases in the US between 1983 and 2010 revealed a mean award of $\$ 1.57$ million..$^{38,39}$ Thus, from the perspectives of patient care and litigation, recognition and appreciation of CES are necessary for appropriate management.

Variability in clinical presentation may prolong diagnosis and surgical intervention for CES, which has important medicolegal ramifications. ${ }^{37}$ In a review of US CES malpractice cases, Daniels et al. reported that most cases $(73.3 \%$ ) did not present with the defining bowel or bladder dysfunction presumed for CES diagnosis; furthermore, most cases $(83.3 \%)$ ruled in favor of the plaintiff also did not have the classic CES presentation..$^{40}$ Many patients $(43 \%)$ lacked urinary dysfunction in a report of CES cases in the UK by Todd ${ }^{41}$ Following diagnosis of CES, early decompressive surgery within 48 hours is crucial for improving prognosis. Nielsen et al. reported return of normal detrusor contraction in $72.7 \%$ versus $30 \%$ of patients who received surgery $<48$ hours and $>48$ hours, respectively, after CES symptom onset..$^{42}$ Similarly, Shapiro found $100 \%$ versus $33 \%$ resolution of urinary and stool incontinence with surgeries performed $<48$ hours and $>$ 48 hours, respectively. ${ }^{43}$ Both Shapiro and Ahn et al. separately found statistically higher risks for persistent bladder incontinence, motor deficit, pain, and sexual dysfunction with delayed surgery. ${ }^{36,43}$ Likewise, time to surgery was significantly associated with plaintiff verdict in the study by Daniels et al. ${ }^{40}$

\section{Death}

In the context of spine surgery, intraoperative or perioperative death may occur from acute blood loss, cardiac arrest, anaphylaxis, massive pulmonary embolism, septic shock, pneumonia, acute respiratory distress disorder, or massive stroke. These outcomes may be a direct cause of the disease or injury being treated, due to technical aspects of the operation being performed, administration of anesthesia, preexisting medical conditions, incidents occurring in the postoperative period, or some combination of the above. Administration of a general anesthetic, required to perform most spine surgeries, carries a small risk of death itself. The risk of death from anesthesia was estimated to be 1 in 5500 cases in 1960 to 1 in 26,000 in $1984 .{ }^{44}$ Reaction to drugs used for general anesthesia may cause anaphylaxis, cardiac arrythmias, liver necrosis, or malignant hyperthermia. A study of National Health Service hospitals in the UK found that anesthesia played a role in $14.1 \%$ of deaths reported in the intraoperative and perioperative period..$^{45}$ Almost all inhalational anesthetic agents cause some degree of peripheral vasodilation and cardiac depression, which may cause myocardial ischemia. ${ }^{46}$

Unsurprisingly, patient death is a major aspect of litigation brought against neurosurgeons. In a recent analysis by Elsamadicy et al., ${ }^{11} 17.4 \%$ of claims brought against neurosurgeons involved patient death. Of all claims against neurosurgeons involving patient death, displacement of intervertebral disc was the most common associated medical condition, with an average payment of $\$ 457,222$. In these cases, improper performance of the procedure resulted in the highest total payments $(\$ 330,500$ average payout per claim) in cases involving patient death.

\section{Ethical Considerations}

The successful practice of spinal neurosurgery is founded not only on technical excellence, knowledge, and clinical acumen, but also on an unwavering commitment to high ethical standards. Ethics is a foundational principle in medicine, highlighted by the recitation of the Hippocratic Oath by medical students to "First do no harm."47 In the context of spine surgery, ethical behavior involves avoiding any intentional wrongdoing or harm to patients, respecting the wishes and dignity of patients, surgeons setting appropriate limitations on their scope of practice, and prompt disclosure of errors or complications to patients and their families.

The prompt disclosure of errors or complications to patients and their families is now universally advocated by patient safety organizations, experts, and physician groups. ${ }^{48}$ Since the publication of To Err Is Human by the Institute of Medicine in 1999, there has been increased attention on the need for transparency between providers and patients regarding medical errors. ${ }^{49}$ Although the risk of malpractice may be invoked as an obstacle of physician disclosure of errors, there is evidence that lack of transparency about errors and complications increases the risk of litigation. In a review of malpractice claims, $10 \%$ of claims cited failure to provide an explanation as motivation for pursuing litigation. ${ }^{50}$ Conversely, there is evidence that clear communication of errors to patients does not increase the risk of litigation. In 2002, an act was passed in Pennsylvania mandating the written and verbal disclosure of serious events to patients. The implementation of this act 
was not associated with an increase in medical malpractice claims. ${ }^{51}$ In 2001, the University of Michigan Health System (UMHS) implemented a program mandating full disclosure of medical errors to patients along with prompt compensation. Since the implementation of this program, UMHS has experienced a significantly decreased rate of malpractice claims, total payouts, and liability cost. ${ }^{52}$

\section{Conclusions}

Spinal neurosurgery is among the highest litigated specialties due to the possibility of permanent disability from the natural history of the conditions being treated, the need for instrumentation placed in close proximity to vital neurovascular structures, and the unforgiving nature of the spinal cord and nerve roots to traumatic or iatrogenic injury. Tort reform is an important geographic determinant on the rate of malpractice claims levied against neurosurgeons and the average amount awarded per claim. Overall, the rate of malpractice claims appears to be trending downward, but the amount awarded per claim has increased. Like other surgical subspecialties, wrong-sided surgery is considered a sentinel event with high risk for litigation, but the complex segmental anatomy of the human spinal column creates the possibility of wrong-level surgery, which is also highly litigated. In addition, spine surgeons treat conditions requiring prompt diagnosis and neurosurgical intervention to mitigate long-term disability, such as CES or incomplete spinal cord injury, which are also at increased risk for litigation. Prompt disclosure of medical errors and complications to patients has been associated with reduced rates of litigation. Above all, maintaining high ethical standards in the face of complications is critical in spine surgery.

\section{Acknowledgments}

This article was completed with time and support from the Council of State Neurosurgical Societies.

\section{References}

1. Jena AB, Seabury S, Lakdawalla D, Chandra A. Malpractice risk according to physician specialty. $N$ Engl J Med.2011; 365(7):629-636.

2. Mello MM, Studdert DM, Brennan TA. The new medical malpractice crisis. N Engl J Med. 2003;348(23):2281-2284.

3. Boutin PR. The medical malpractice crisis: is the medical review committee a viable and legal alternative? Santa Clara Law Rev. 1975;15:405.

4. US Department of Health, Education, and Welfare. Medical Malpractice: Report of the Secretary's Commission on Medical Malpractice. US Department of Health, Education, and Welfare; 1973.

5. Posner JR. Trends in medical malpractice insurance, 19701985. Law Contemp Probl. 1986;49(2):37-56.

6. Nelson LJ III, Morrisey MA, Kilgore ML. Damages caps in medical malpractice cases. Milbank Q. 2007;85(2):259-286.

7. Olsen RN. The reform of medical malpractice law: historical perspectives. Am J Econ Sociol. 1996;55(3):257-275.

8. National Practitioner Data Bank. Public use data file. U.S. Department of Health and Human Services. Accessed September 15, 2020. https://www.npdb.hrsa.gov/resources/ publicData.jsp

9. Thomas R, Gupta R, Griessenauer CJ, et al. Medical mal- practice in neurosurgery: a comprehensive analysis. World Neurosurg. 2018;110:e552-e559.

10. Rovit RL, Simon AS, Drew J, et al. Neurosurgical experience with malpractice litigation: an analysis of closed claims against neurosurgeons in New York State, 1999 through 2003. J Neurosurg. 2007;106(6):1108-1114.

11. Elsamadicy AA, Sergesketter AR, Frakes MD, Lad SP. Review of neurosurgery medical professional liability claims in the United States. Neurosurgery. 2018;83(5):997-1006.

12. Agarwal N, Gupta R, Agarwal P, et al. Descriptive analysis of state and federal spine surgery malpractice litigation in the United States. Spine (Phila Pa 1976). 2018;43(14):984-990.

13. National Spinal Cord Injury Statistical Center. Facts and figures at a glance. University of Alabama at Birmingham; 2018. Accessed September 15, 2020. https://www.nscisc.uab. edu/Public/Facts\%20and\%20Figures\%20-\%202018.pdf

14. Daniels AH, Ruttiman R, Eltorai AEM, et al. Malpractice litigation following spine surgery. J Neurosurg Spine. 2017; 27(4):470-475.

15. Quigley RS, Akpolat YT, Forrest BD, et al. Reason for lawsuit in spinal cord injury affects final outcome. Spine (Phila Pa 1976). 2015;40(11):851-855.

16. Lekovic GP, Harrington TR. Litigation of missed cervical spine injuries in patients presenting with blunt traumatic injury. Neurosurgery. 2007;60(3):516-523.

17. Studdert DM, Mello MM, Sage WM, et al. Defensive medicine among high-risk specialist physicians in a volatile malpractice environment. JAMA. 2005;293(21):2609-2617.

18. Jarvik JG, Gold LS, Comstock BA, et al. Association of early imaging for back pain with clinical outcomes in older adults. JAMA. 2015;313(11):1143-1153.

19. Emery DJ, Shojania KG, Forster AJ, et al. Overuse of magnetic resonance imaging. JAMA Intern Med. 2013;173(9): 823-825.

20. Devine J, Chutkan N, Norvell DC, Dettori JR. Avoiding wrong site surgery: a systematic review. Spine (Phila $\mathrm{Pa}$ 1976). 2010;35(9 suppl):S28-S36.

21. Anonymous. Patient safety first alert-implementing a correct site surgery policy and procedure. AORN J. 2002;76(5): 785-788.

22. James MA, Seiler JG III, Harrast JJ, et al. The occurrence of wrong-site surgery self-reported by candidates for certification by the American Board of Orthopaedic Surgery. J Bone Joint Surg Am. 2012;94(1):e2.

23. Longo UG, Loppini M, Romeo G, et al. Errors of level in spinal surgery: an evidence-based systematic review. J Bone Joint Surg Br. 2012;94(11):1546-1550.

24. Mody MG, Nourbakhsh A, Stahl DL, et al. The prevalence of wrong level surgery among spine surgeons. Spine (Phila Pa 1976). 2008;33(2):194-198.

25. Goodkin R, Laska LL. Wrong disc space level surgery: medicolegal implications. Surg Neurol. 2004;61(4):323-341.

26. Vachhani JA, Klopfenstein JD. Incidence of neurosurgical wrong-site surgery before and after implementation of the universal protocol. Neurosurgery. 2013;72(4):590-595.

27. Algie CM, Mahar RK, Wasiak J, et al. Interventions for reducing wrong-site surgery and invasive clinical procedures. Cochrane Database Syst Rev. 2015;(3):CD009404.

28. Devine JG, Chutkan N, Gloystein D, Jackson K. An update on wrong-site spine surgery. Global Spine J. 2020;10(1 sup$\mathrm{pl}): 41 \mathrm{~S}-44 \mathrm{~S}$.

29. Groff MW, Heller JE, Potts EA, et al. A survey-based study of wrong-level lumbar spine surgery: the scope of the problem and current practices in place to help avoid these errors. World Neurosurg. 2013;79(3-4):585-592.

30. Hsiang J. Wrong-level surgery: a unique problem in spine surgery. Surg Neurol Int. 2011;2:47.

31. Nassr A, Lee JY, Bashir RS, et al. Does incorrect level needle localization during anterior cervical discectomy and fusion 
lead to accelerated disc degeneration? Spine (Phila Pa 1976). 2009;34(2):189-192.

32. Mayer JE, Dang RP, Duarte Prieto GF, et al. Analysis of the techniques for thoracic- and lumbar-level localization during posterior spine surgery and the occurrence of wrong-level surgery: results from a national survey. Spine J. 2014;14(5): 741-748.

33. Vitale M, Minkara A, Matsumoto H, et al. Building consensus: development of best practice guidelines on wrong level surgery in spinal deformity. Spine Deform. 2018;6(2): 121-129.

34. Patel A, Runner RP, Bellamy JT, Rhee JM. A reproducible and reliable localization technique for lumbar spine surgery that minimizes unintended-level exposure and wrong-level surgery. Spine J. 2019;19(5):773-780.

35. Fager CA. Malpractice issues in neurological surgery. Surg Neurol. 2006;65(4):416-421.

36. Ahn UM, Ahn NU, Buchowski JM, et al. Cauda equina syndrome secondary to lumbar disc herniation: a meta-analysis of surgical outcomes. Spine (Phila Pa 1976). 2000;25(12): $1515-1522$.

37. Kostuik JP. Medicolegal consequences of cauda equina syndrome: an overview. Neurosurg Focus. 2004;16(6):e8.

38. Gardner A, Gardner E, Morley T. Cauda equina syndrome: a review of the current clinical and medico-legal position. Eur Spine J. 2011;20(5):690-697.

39. Markham DE. Cauda equina syndrome: diagnosis, delay and litigation risk. J Orthop Med. 2004;26(3):102-105.

40. Daniels EW, Gordon Z, French K, et al. Review of medicolegal cases for cauda equina syndrome: what factors lead to an adverse outcome for the provider? Orthopedics. 2012;35(3): e414-e419.

41. Todd NV. Causes and outcomes of cauda equina syndrome in medico-legal practice: a single neurosurgical experience of 40 consecutive cases. Br J Neurosurg. 2011;25(4):503-508.

42. Nielsen B, de Nully M, Schmidt K, Hansen RI. A urodynamic study of cauda equina syndrome due to lumbar disc herniation. Urol Int. 1980;35(3):167-170.

43. Shapiro S. Cauda equina syndrome secondary to lumbar disc herniation. Neurosurgery. 1993;32(5):743-747.

44. Holland R. Anaesthetic mortality in New South Wales. Br J Anaesth. 1987;59(7):834-841.

45. Lunn JN, Devlin HB. Lessons from the confidential enquiry into perioperative deaths in three NHS regions. Lancet. 1987; 2(8572):1384-1386.

46. Sharma BR. Death during or following surgical procedure and the allegation of medical negligence: an overview. J Forensic Leg Med. 2007;14(6):311-317.

47. Askitopoulou H, Vgontzas AN. The relevance of the Hippocratic Oath to the ethical and moral values of contemporary medicine. Part II: Interpretation of the Hippocratic Oath-today's perspective. Eur Spine J. 2018;27(7):1491-1500.
48. Mazor KM, Simon SR, Gurwitz JH. Communicating with patients about medical errors: a review of the literature. Arch Intern Med. 2004;164(15):1690-1697.

49. Institute of Medicine Committee on Quality of Health Care in America; Kohn LT, Corrigan JM, Donaldson MS, eds. To Err Is Human: Building a Safer Health System. National Academies Press (US); 2000.

50. Beckman HB, Markakis KM, Suchman AL, Frankel RM. The doctor-patient relationship and malpractice. Lessons from plaintiff depositions. Arch Intern Med. 1994;154(12): $1365-1370$.

51. Painter LM, Kidwell KM, Kidwell RP, et al. Do Written disclosures of serious events increase risk of malpractice claims? One health care system's experience. J Patient Saf. 2018;14(2):87-94.

52. Kachalia A, Kaufman SR, Boothman R, et al. Liability claims and costs before and after implementation of a medical error disclosure program. Ann Intern Med. 2010;153(4): 213-221.

53. National Practioner Data Bank. U.S. Department of Health \& Human Services. Accessed September 15, 2020. https://www. npdb.hrsa.gov/

\section{Disclosures}

Dr. Veeravagu reports being a consultant to NuVasive, Stryker, OsteoCentric, and Surgical Theater, and having direct stock ownership in ATEC.

\section{Author Contributions}

Conception and design: Veeravagu, Varshneya. Acquisition of data: Veeravagu, Medress. Analysis and interpretation of data: all authors. Drafting the article: Veeravagu, Medress, Jin, Feng. Critically revising the article: all authors. Reviewed submitted version of manuscript: Veeravagu, Medress, Feng, Varshneya. Approved the final version of the manuscript on behalf of all authors: Veeravagu. Administrative/technical/material support: Veeravagu. Study supervision: Veeravagu, Medress.

\section{Correspondence}

Anand Veeravagu: Stanford University, Stanford, CA. anandv2@ stanford.edu. 